\title{
Effect of chemical and bio-fertilizers on the life table attributes of Eisenia fetida
}

\author{
Mamta Passi \\ Department of Zoology, Maharshi Dayanand University, Rohtak - 124001 (Haryana), India \\ Vineeta Shukla* iD \\ Department of Zoology, Maharshi Dayanand University, Rohtak - 124001 (Haryana), India \\ Pinky Deswal \\ Department of Zoology, Maharshi Dayanand University, Rohtak - 124001 (Haryana), India \\ *Corresponding author Email: prof.vineetashukla@gmail.com
}

\section{Article Info}

https://doi.org/10.31018/

jans.v13i4.2973

Received: September 3, 2021

Revised: December 7, 2021

Accepted: December 13, 2021

\section{How to Cite}

Passi, M. et al. (2021). Effect of chemical and bio-fertilizers on the life table attributes of Eisenia fetida. Journal of Applied and Natural Science, 13(4), 1524 - 1530. https://doi.org/10.31018/jans.v13i4.2973

\begin{abstract}
Earthworms are important soil invertebrates and play an important role in improving soil quality. Indiscrete use of chemical fertilizers poses a threat to soil quality. Alteration in the soil chemistry is known to negatively impact the macrofauna of soil, especially, epigeic earthworms. The study aimed to understand the effect of chemical and biological fertilizers on the life table attributes of earthworm, Eisenia fetida. Laboratory adapted E. fetida were reared on artificial soil supplemented with chemical fertilizers, Urea and DAP, and biofertilizers, vermicompost and Rutoz ${ }^{\circledR}$.It was observed that the presence of urea in soil proved to be detrimental to the biomass accumulation, life span, as well as reproductive potential of the earthworms. Application of urea to the soil harbouring earthworms reduced the weight of individual earthworms from $286 \pm 14.24 \mathrm{mg}$ in the control group to $242 \pm 12.047 \mathrm{mg}$ as soon as 15 days of the application, while the DAP diminished the earthworm weight to $272 \pm 13.54 \mathrm{mg}$. The effect was more pronounced on the total biomass of the culture owing to the high toxicity of urea. The total mass diminished to one-third,i.e., $1.02 \pm 0.05 \mathrm{~g}$ on Day 60 as compared to the corresponding control $(3.46 \pm 0.172 \mathrm{~g})$. The urea and DAP treatment decreased the percent survival of the earthworms by $70 \%$ and $40 \%$, respectively.On the other hand, the bio-fertilizers had a positive effect on the earthworms and the biology is comparable to that of the control group. To the best of our knowledge, this is the first attempt to understand the effect of chemical fertilizers on the survival and reproductive fitness of the worms.
\end{abstract}

Keywords: Bio-fertilizers, Biomass, Cocoon, Chemical fertilizers, Earthworm, Eisenia fetida

\section{INTRODUCTION}

Earthworms, 'the intestine of earth' are found in cool moist soil. Earthworms till the soil and help to improve the soil structure with soil aeration, better drainage and improved nutrient content (Sizmur et al., 2011a,b; Jusselme et al.,2013) with an increasing population of useful microbes. Earthworms represent a major soil fauna and play significant roles in improving the yield capacity of the land mass they live in (Matlok,2020). As they live in close vicinity of plants, they accidentally become prone to ill effects of agrochemicals, i.e., fertilizers, pesticides, herbicides etc. (Byambas et al., 2019). In soil-toxicological studies, the earthworm is widely used as a model experimental animal for toxicity testing as recommended by European Economic Community (European Economic Community, 1985, Ali and Kashem, 2018, Raza et al.,2021).
Nowadays, the use of chemical fertilizers has become an indispensable aspect of agricultural practice. Fertilizer (chemical /organic) input has become a decisive step in crop yield and economic returns too. Fertilizer application helps to replenish the nutrient consumed by the previous crop. The impact of each artificially synthesized substance, especially pesticides or fertilizers, was assessed on crop quality and soil-fauna (Singh and Gupta,2018). Earthworms are the most important as well as the dominant fauna of all the soil macrofauna. Therefore, each change in the soil composition affects the earthworms either directly or indirectly.

The chemical fertilizers are not always negative to the soil inhabitants,i.e., earthworms. Few studies also show an increase in food supply to earthworms due to the increased production and thus more foliage on the ground (Whalen et al.,1998). Other studies concluded the neutral effect of the fertilizers on earthworms (Lofs- 
holmin, 1983). Though, the reports of the negative impact of fertilizer and pesticide application are plenty (Miglani and Bisht, 2019).

Several studies have already been conducted to demonstrate the harmful effects of pesticides and fertilizers on the soil. The growing food demand has left no choice but to use fertilizers and pesticides to meet the growing global food demands (Laucka et al., 2020). These chemicals alter the soil chemistry that adversely affect the soil fauna, thereby disturbing the soil ecosystem (Liang et al., 2007).The residual pesticides are toxic to the soil macrofauna, including earthworms (Saxena et al., 2014). The effect of the fertiliser application on soil macrofauna, especially the earthworm, is a need of the hour.Therefore, the present study was designed to access the effect of use of chemical and organic fertilizers on the life table attributes of Eisenia fetida.

\section{MATERIALS AND METHODS}

\section{Biological material}

E. fetida were procured from Godhan unit, Bahadurgarh (Haryana), a private firm engaged in the production of vermi-fertilizer. Worms were brought to the laboratory at Maharshi Dayanand University, Rohtak, Haryana and were identified using the online available taxonomic key and digital library (Thakur and Yadav, 2018). The worms were thus, identified and confirmed as $E$. fetida.

\section{Culture of earthworms}

The laboratory-adapted earthworms were kept $27 \pm$ $20^{\circ \mathrm{C}}$ in big culture pots for $5-6$ months to be acclimatized in the laboratory conditions. The acclimatized earthworms were reared in earthen pots (Volume 10 Lts.) to mimic the natural soil conditions. The experimental setup was maintained as per the recommendations of OECD guidelines number 207 (1984) and 222 ISO $(1993,1998)$ for testing of chemicals (Organization for Economic Co-operation and Development, 2004). The earthworms were fed with $1.5 \%$ agarose gel to replace the organic matter in the gut. A group of mature, healthy agarose fed, earthworms of approximately the same body weight and length (approx 270-300 mg) were used in the experimental model (Lodrache and Borza, 2010).

\section{Preparation of tropical artificial soil}

Tropical artificial soil was prepared in the laboratory. For this purpose, Cocopeat (10\%) and crushed Eggshells as a source of calcium carbonate were mixed thoroughly in Industrial sand $(70 \%)$, and clay $(15 \%)$. The $\mathrm{pH}$ of the final mixture was adjusted to $6.0 \pm 0.5$ units with the addition of lime. The mixture, thus, formed was referred as tropical artificial soil.35-40dayold air-dried cow dung powder was used to supplement the nutritive medium (Neuhauser and Callahan, 1990). The soil was watered on alternate days to avoid drying. Before the onset of experiments, the worms were acclimatized in the setup for 24 hours.

\section{Test chemicals}

The chemical fertilizers, $\mathrm{N}-46 \%$ Urea and Diammonium phosphate (DAP- $\mathrm{P}_{2} \mathrm{O}_{5}-46 \%, 18 \% \mathrm{~N}$ ) manufactured by Indian Farmers Fertilizer Cooperative Limited (IFFCO) and biofertilizer-Rutoz $\AA$ (Coromandel) were procured from the local market. Similarly, vermicompost was also procured from Godhan unit, Bahadurgarh (Haryana), along with the vermiculture.

\section{Methodology}

Laboratory-adapted E.fetida were evaluated for the effect of urea, DAP, Rutoz® biofertilizer and vermicompost on the biomass accumulation, reproduction and life span of the earthworms. Test was conducted in replicates of four for each treatment set in artificial soil. The earthworms without any treatment were also maintained alongside to control the environment-induced confounding growth factors and labelled as $\mathrm{T}_{0}$. $\mathrm{LC}_{50}$ of the chemical fertilizers was determined by plotting percent mortality of the worms against the concentrations of the chemical fertilizers, urea or DAP. The results were used to determine the concentrations of the fertilizers to be used. The urea $\mathrm{LC}_{50}$ was $876.56 \mathrm{mg} / \mathrm{kg}$, while the DAP LC 50 was $2098.69 \mathrm{mg} / \mathrm{kg}$ of soil. Ten adult E.fetida worms were inoculated with test chemicals, i.e., Urea and DAP, in each pot of artificial soil neatly labelled as control or treatment sets with a number of days of harvesting. In the treatment sets, earthworms were exposed to T1 $(438.28 \mathrm{mg} / \mathrm{Kg}$ Urea) and T2 (1049.345 mg/Kg DAP) sub-lethal doses ( $\mathrm{mg} / \mathrm{kg}$ of artificial soil) of commercially available chemical fertilizers. In the treatment set T3, $1000 \mathrm{mg}$ of Rutoz $\AA$ biofertilizer per $\mathrm{kg}$ of artificial soil was added, and for the treatment set, T4,1000 $\mathrm{mg}$ of vermicompost per $\mathrm{kg}$ of artificial soil was added. Finely grounded air-dried cow dung as food for the earthworms was supplemented per week. Earthen pots were covered with a thin muslin cloth to maintain proper aeration and moisture level and to prevent the earthworms from escaping the pots. Initially, pots were monitored daily to observe any unusual behaviour for up to 7 days. The earthworms were harvested on 1,15, 30,45, and 60 days for the determination of the biomass and reproductive potential in terms of the number of cocoons formed and the juveniles produced. The worms were visually inspected carefully to record any change in their morphology and the observation was neatly recorded.

\section{Biomass accumulation}

For Biomass accumulation, the earthworms were handpicked from each treatment set upon completion of the 
time interval decided for the experiment. The worms were washed carefully with distilled water to remove the mud attached to their bodies. The worms were dried and weighed (Senpati and Dash 1984).

\section{Reproductive potential}

The reproductive potential of the worms was estimated by counting the numbers of the cocoon in the cultures. For this purpose, ten earthworms were kept in each earthen pot containing artificial soil and powdered cow dung and neatly labelled as control and treatment pots as described above. The earthworms were allowed to mate and reproduce. Fifteen days onwards, the cocoons in each pot were counted and recorded at an interval of 15 days each up to 60 days of setup. Similarly, the juveniles were counted in the pots from 30 days onwards at a regular interval of 15 days up to 60 days of the setup.

\section{Statistical analysis}

Each experiment was repeated thrice with four replicates each time. The arithmetic mean and standard deviation were calculated as a measure of the central tendency and dispersion around the mean. The Skewness and Kurtosis of the data was estimated to check the normalcy of the distribution. A two-way analysis of variance was employed to understand the significance of the differences among the treatment data as well as the day-wise data. The longevity data was analysed as described by Sharma et al. (2013). Log-Rank Test was employed to understand the significance of differences in longevity between the groups. Further, Kaplan Meier Survival Analysis was employed to generate a plot depicting the Survival Function of the earthworms reared on soil treated with different nitrogen sources at $95 \%$ confidence Interval.

\section{RESULTS AND DISCUSSION}

\section{Biomass of $E$. fetida reared on different nitrogenous compounds}

The present study showed no effect of the chemical or organic fertilizer on day 1 among the weight of the earthworms of each treatment with chemical and organic fertilizer. However, the difference became evident with time (Fig. 1). On the Day-15 and Day-30, a decrease in weight was noticed in the weight of individual earthworms grown on soil treated with urea and DAP. The weight of the earthworms reared on Urea supplemented soil was $340.00 \pm 17 \mathrm{mg}$ and those of reared on the DAP treated soil was $340.00 \pm 27 \mathrm{mg}$; reared on the Rutoz $®$ treated soil was $364.45 \pm 18 \mathrm{mg}$, and those on vermicompost treated soil was $388.00 \pm 19 \mathrm{mg}$ on the $60^{\text {th }}$ day against $384.45 \pm 19 \mathrm{mg}$ in the respective control group.
The growth of the E. fetida was evident in all the treatments, with significant changes in the worm weights at an interval of every 15 days. Two-way anaysis of variance (ANOVA) carried out to test the significance of the differences among the days of development as well as among the treatment groups revealed that the differences were highly significant with a F value of 16.904, degree of freedom 4 and $p$ value $<0.0001$ among the days of growth. Similarly, the ANOVA test for treatments gives a $F$ value of 3.342 with df 4 and a significant $p$ value of $>0.05$.

The mean value of weight per earthworm was found to increase with time in all the treatments. However, considering the mortality occurring in the earthworms changed the complete scenario. The longevity of the earthworms grown on various nitrogen supplements is shown in Figs. 2a,b. The differences in the longevity of the earthworms grown on differentially treated soils were tested using Kaplan Meier Survival Analysis. The Kaplan Meier analysis generated a plot depicting the Survival Function of the earthworms reared on soil treated with different nitrogen sources at 95\% confidence Interval. Log-Rank Test on survival revealed a chi statistic value of 25.579 and a highly significant $p$ value of less than 0.0001 , confirming the significance of the differences between the life span of the earthworm reared on differentially treated soils with different nitrogenous sources.

The weight of individual earthworms increased with age (Fig.1). However, the comparison of net biomass of the entire culture was significantly decreased when the soil was treated with chemical fertilizers, Urea and DAP, possibly due to high mortality (Figs 2a,b). The mortality adjusted weight of a replicate culture with initial 10 numbers of earthworms is depicted in Fig. 3. The nitrogenous source, especially the chemicals, were found to have a significant negative impact on the biomass of the earthworm cultures. However, the impact was confounded by the toxicity of the chemical

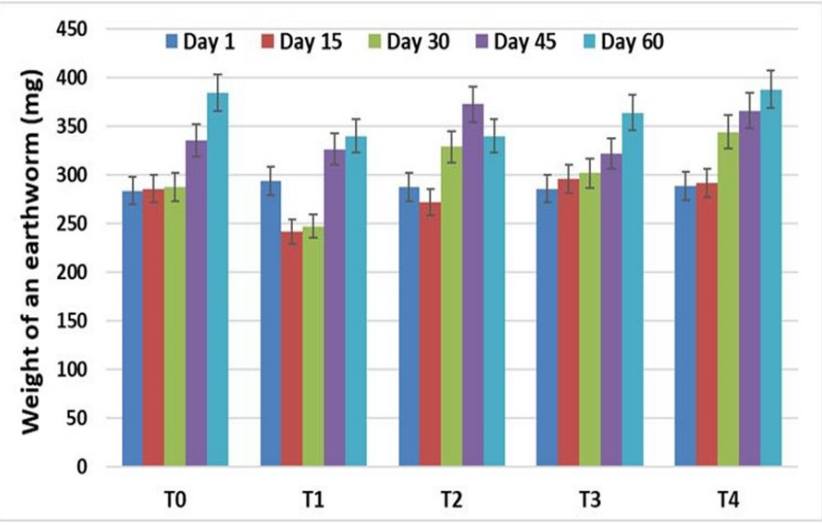

Fig. 1. Mean weight per earthworm on 15 days interval each till 60 days, when reared on the soil treated with different nitrogen sources. $[T 0=$ Control; $T 1=$ Urea; $T 2=$ $D A P ; T 3=$ Rutoz $\AA ; T 4=$ Vermi-compost $]$ 
nitrogen supplements as surmised by a steep decline in the weight of the urea-treated culture to $1.020 \pm 0.051$ $\mathrm{g}$ at 60 days and that of the DAP-treated culture to 2.04 $\pm 0.98 \mathrm{~g}$ against $3.46 \pm 0.169 \mathrm{~g}$ of the control culture. The cultures that were reared on the bio-fertilizers and vermicompost were quite healthy compared to that of the control. Two-way ANOVA revealed an F statistic value of 5.097 at $d f=4$, resulting in a significant $p$ value $<0.01$ in the case of differences among the treatments. However, the differences among the time periods were insignificant.

Growth is a direct indicator of health conditions and the food they are exposed to (Meharaj and Manivannan, 2015). Our results revealed that in the presence of urea, the body-weight of the worms was negatively affected. One may associate the reduced biomass of the earthworms to the physiological stress (weakened with less body weight) they are facing as a result of the altered microenvironment, as was observed due to the pesticide applications (Zhou et al.,2008). Similar results were reported by other workers as well in earthworms, e.g. Eisenia fetida grown on chemical fertilizers (Lodrache and Borza, 2010; Rai et al.,2014).

The results of the present study revealed that the toxicity of the chemical fertilizers, Urea and DAP was detrimental to the culture of $E$. fetida.It has been demonstrated earlier that the use of application of urea in the soil changes the soil chemistry, as evidenced by increased soil $\mathrm{pH}$ and ammonia levels. These changes have been reported to be detrimental to the soil microflora (Geisseler and Scow, 2014; Staley et al., 2018). The toxicity of the urea may also be attributed to urea induced alterations in the soil chemistry. Toxicity of DAP to earthworm (Eudrilus eugeniae) cultures has also been reported previously (Chaudhari, 2016).

The use of chemical fertilizer need not necessarily be negative. The tolerance of a chemical fertilizer has been reported to vary in different fertilizers (Edwards

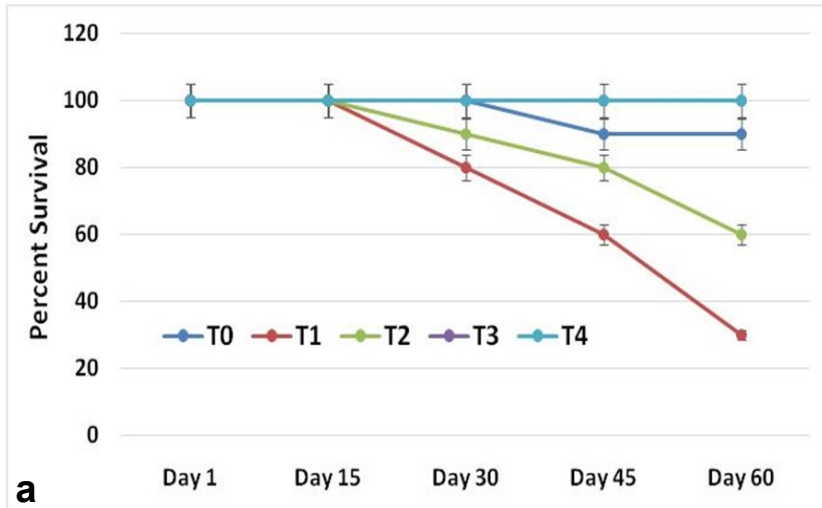

Fig. 2. (a). Percent survival of earthworms per 15 days when reared on the soil treated with different nitrogen

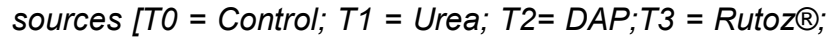
T4 = Vermi-compost] and Lofty, 1982). The effect of the fertilizers on the macrofauna,including earthworms, is also reported to vary from species to species, probably attributed to differences in their physiology and biology (Yahyaabad et al., 2018). The epigeic species such as E. fetida that feed on the surface matter are more prone to the chemical changes in the surface soil as compared with different anecic species,e.g. L. terrestris that dig subsurface vertical burrows (Yahyaabadi et al., 2018).

\section{Reproductive fitness of the earthworms grown on different nitrogenous supplements}

The present study showed (Fig.4a) that a sum of 34.00 \pm 0.49 cocoons per culture was formed on day 60 in the control group, while only $11.00 \pm 0.50$ cocoons per culture were formed when reared on urea-treated soil, and $16.00 \pm 0.498$ cocoons/culture were formed when reared on the DAP-treated soil. The reproductive capacity of the earthworms (Fig. 4a,b) reared on natural nitrogen supplements like Rutoz ${ }^{\circledR}$ and Vermicompost were comparable to that of the respective control on Day 60 with $36.00 \pm 0.697$ and $44.00 \pm 0.846$ cocoons per culture, respectively. Two-way analysis of variance confirmed the significance of the differences obtained in the cocoon formed per culture among the treatment groups with $\mathrm{F}$ value $=4.36$; $\mathrm{df}=4$ and a $\mathrm{p}$-value of $<$ 0.05 . Similarly, the differences in the days were also found significant with $F$ value $=10.75$; $d f=3$ and $a p$ value of $<0.005$.

In the control group of earthworm culture, $34.00 \pm 1.485$ juveniles per culture were hatched on day 60 ; while in the urea-treated soil,only $6.00 \pm 0.365$ juveniles per culture were hatched; and in the DAP-treated soil 16.00 \pm 0.498 juveniles/culture were hatched (Fig. 4a,b). As was observed in the case of the cocoons formed, the juveniles hatched per earthworm culture reared on Rutoz $®$ and Vermicompost were comparable to that of the respective control on Day 60 with $33.00 \pm 1.44$ and

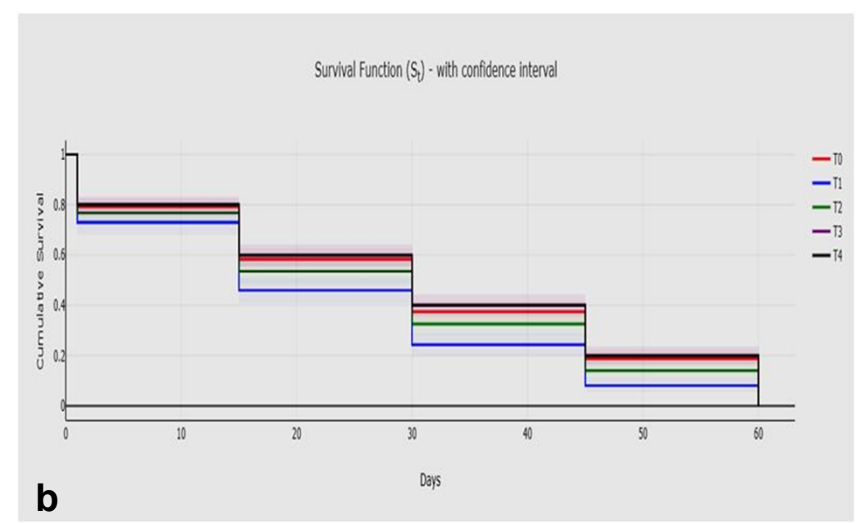

(b) Kalpan-Meier Plot depicting the Survival Function of the earthworms reared on soil treated with different nitrogen sources at $95 \%$ confidence Interval. [T0 = Control; T1 = Urea; T2= DAP; T3 = Rutoz $® ;$ T4 = Vermi-compost] 
$42.00 \pm 1.539$ juveniles per culture, respectively. Twoway analysis of variance confirmed the significance of the differences obtained in the juveniles hatched per culture among the treatment groups with a $\mathrm{F}$ value $=$ 19.795; $\mathrm{df}=4$ and a $\mathrm{p}$ value of $<0.01$. Similarly, the differences in the days were also found significant with a $F$ value $=10.61 ; d f=1$ and a $p$ value of $<0.05$.

The reproduction of the members of culture is crucial for the continuation of its race. The formation of cocoon and hatching of juveniles in the earthworms reared on soil supplemented with urea was found to be nearly reduced to one-third of the control, and in the worms reared on the DAP treated soil it was reduced to nearly half. The results are alarming. However, the sample size is too small to infer the situation at the field level. In addition, under natural conditions, a number of confounding factors control the life table attributes of an organism.

To the best of our knowledge, this is the first report detailing the effect of chemical-based fertilizers on the reproductive fitness of the worms. However, literature is available on the effect of chemical pesticides on the reproduction of earthworms. The use of chemical pesticides has been shown to be detrimental to the reproductive potential of the worms. The earthworms thriving on pesticide-contaminating soil were found to have compromised cocoon formation and hatching, esp., at higher concentrations (Yasmin and D'Souza, 2010). The effect of the chemicals varied with a number of factors such as the species of the earthworms, type and quantity of the pesticide chemical, soil characteristics, and so on (Roriguez- Campos et al., 2014).

The use of chemical fertilizers, along with the use of pesticides, better irrigation methods and the use of genetically superior quality seeds, had revolutionized the agriculture sector. However, indiscrete use of the chemicals in the fields has posed a number of problems with time such as soil pollution, adverse effects on farmer's health, incorporation of the chemicals in the food chain and resulting bio-amplification. The negative

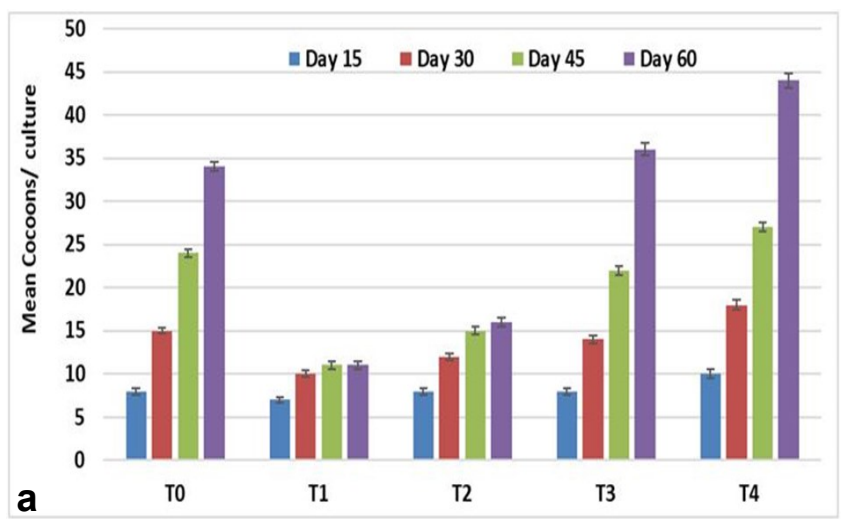

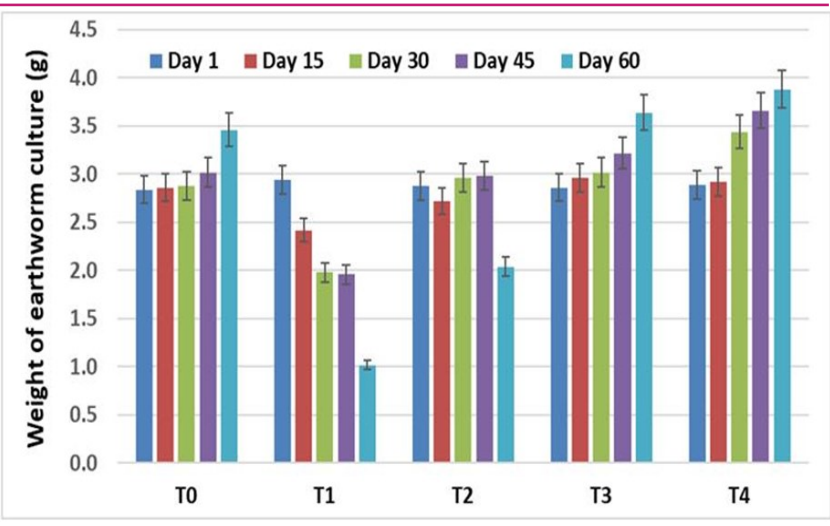

Fig. 3. Weight per earthworm culture on 15 days interval each till 60 days, when reared on the soil treated with different nitrogen sources. $[T 0=$ Control; T1 = Urea; T2=

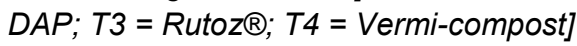

effect of these residual chemicals on the macrofauna is another concern. The present study has clearly pointed towards the decline biomass, longevity and reproductive fitness of the culture of laboratory acclimatized earthworms, E.fetida. One may correlate the decline in biomass and reproductive fitness with the chemicalbased fertilizer induced toxicity. However, the present study is carried out in laboratory conditions. The authors are fully aware that a number of factors confound the life table attributes of a population under natural conditions. Nevertheless, the ability to control most of the confounding factors in the laboratory has its own advantages. The exposure of earthworms to toxic chemical fertilizer has its own consequences. The net outcome of the effect of these chemicals is a result of the fine balance between the worm biology and the toxic microenvironment.

\section{Conclusion}

Earthworm, E. fetida reared on soil treated with Urea, DAP, Rutoz ${ }^{\circledR}$ and Vermicompost. Treatment with chemical fertilizers, viz., urea and DAP were found

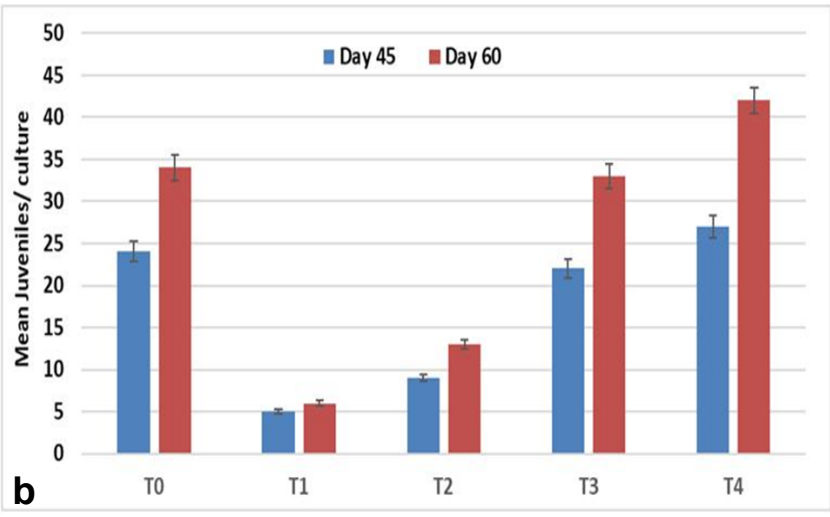

Fig. 4. Reproductive fitness of earthworms. (a) Number of cocoons formed when reared on the soil treated with different nitrogen sources after 15 to 60 days of the setup (b) Number of juveniles formed when reared on the soil-treated with different nitrogen sources after 45 and 60 days of the setup. 
detrimental to the life-table table attributes of the earthworms. Between the two chemical fertilizers used, the use of urea as a soil supplement was more harmful to the earthworms. Since agriculture is largely dependent on chemical fertilizers their prolonged and indiscreet use has posed many ecological problems. The laboratory study needs to be replicated to understand the fertilizer-worm interrelation and ecological damage to macrofauna under field conditions. The outcome may not be the same under field conditions; however, the stress imposed by the chemical fertilizers cannot be neglected.

\section{Conflict of interest}

The authors declare that they have no conflict of interest.

\section{REFERENCES}

1. Ali, S. \& Kashem, M.A.(2018).Life cycle of vermicomposting earthworms Eisenian fetida and Eudrilus eugeniae under laboratory controlled condition. Biomedical Journal of Scientific \& Technical Research. DOI: 10.26717/ BJSTR.2018.10.002015.

2. Byambas, P., Hornick, J.L., Marlier, D. \& Francis, F. (2019).Vermiculture in animal farming: a review on the biological and nonbiological risks related to earthworms in animal feed. Cogent Environ Sci., 5(1),1591328; https:// doi.org/10.1080/23311843.2019.15913-28

3. Chaudhari, M.S. (2016).Acute toxicity of Diammonium phosphate toearthworm (Eudrilus eugeniae). Journal of Entomology and Zoology Studies, 4(6): 501-503.

4. Edwards ,C.A. \& Lofty, J.R. (1982). Nitrogenous fertilizers and earthworm populations in agricultural soils. Soil Biology and Biochemistry,14(5), 515-521. DOI :10.1016/00380717(82)90112-2

5. European Economic Community(1985). Directive79/8331, V, Part C: Methods for the Determination of Ecotoxicity Level 1. DG XI/127-129/82, Rev. 1: Toxicity for Earthworms. Commission of the European Community, Brussels.

6. Geisseler, D., and Scow, K. M. (2014). Long-term effects of mineral fertilizers on soil microorganisms - a review. Soil Biol. Biochem., 75, 54-63.

7. Iordrache, M., \&Borza, I. (2010).Relation between chemical indices of soil and earthworm abundance under chemical fertilization.Plant, Soil and Environment, 56(9), 401407.

8. Jusselme, M.D.,Miambi,E.,. Mora, P., Diouf, M. \&RoulandLefevre,C. (2013) Increased lead availability and enzyme activities in root-adhering soil of Lantana camara during phytoextraction in the presence of earthworms. Sci. Total Environ, 445- 446, 101-109.

9. Laucka, A., Andriukaitis, D., Valinevicius, A.,Navikas, D., Zilys, M.,Markevicius, V.,Klimenta, D., Sotner, R.\&Jerabek, J. (2020). Method for Volume of Irregular Shape Pellets Estimation Using 2D Imaging Measurement. Appl. Sci, 10, 2650.

10. Liang,W., Beattie,G.C.A., Meats, A. \& Spooner-Hart, R. (2007) Impact on soil-dwelling arthropods in citrus orchards of spraying horticultural mineral oil, carbaryl or methidathion. Aust J Entomol,46, 79-85.

11. Lofs-Holmin, A. (1983). Influence of agricultural practices on earthworms (Lumbricidae), Acta. Agric. Scand, (33), 225234.

12. Matlok, N., Szostek, M., Antos, P.,Gajdek, G.. Gorzelany, J.,Bobrecka-Jamro, D., \& Balawejder, M. (2020). Effect of Foliar and Soil Fertilization with New Products Based on Calcinated Bones on Selected Physiological Parameters of Maize Plants. Appl. Sci., 10, 2579

13. Meharaj, I. \& Manivannan, S. (2015). Influence of poultry waste amended with different organic food sources on growth and reproduction performance of indigenous earthworms Lampito mauritii (Kinberg) and Perionyx excavatus (Perrier). Eur . J. Exp. Biol., 5(6),1-6.

14. Miglani, R. \& Bisht, S.S. ( 2019) World of earthworms with pesticides and insecticides. InterdiscipToxicol, 12(2),7182. doi:10.2478/intox-2019-0008

15. Neuhauser, E.F. \& Callahan,C.A. (1990). Growth and reproduction of the Earthworm Eiseniafoetida exposed to sublethal Concentration of Organic chemicals. Soil Biology and Biochemistry, 31,363-366.

16. Organization for Economic Co-operation and Development (1984).Guideline for testing of chemicals No. 207, Earthworm Acute-toxicity Test (Eiseniafetida/andrei). Organization for Economic Co-operation and Development. Paris, France.

17. Organization for Economic Co-operation and Development (2004). Guideline for testing of chemicals No. 222, Earthworm Reproduction Test (Eiseniafetida/andrei). Organization for Economic Co-operation and Development. Paris, France.

18. Rodriguez-Campos, J., Dendooven, L., Bernal, D., Ramos, C.R.(2014).Potential of earthworms to accelerate removal of organic contaminants from soil: A review. Applied Soil Ecology, 79, 10-25. DOI:10.1016/j.apsoil.2014.0 2.010

19. Raza, S.T.,Tang, J.L., Ali, Z., Yao, Z., Bah, H., Iqbal, H. \& $\mathrm{Rn}, \quad X .(2021)$. Ammonia volatilization and greenhouse gases emissions during vermicomposting with animal manures and biochar to rnhance sustainability. Int. J. Environ. Res. Public Health, 18, 178.

20. Rai, N., Ashiya, P.\&Rathore, D.S. (2014). Comparative study on the effect of chemical fertilizers and organic fertilizers on Eisenia foetida.International J. Innov. Res Sci. Eng.Technol.,3(5), 12991-12998.

21. Saxena, P. N., Gupta, S. K. \& Murthy, R. C.(2014). Comparative toxicity of carbaryl, carbofuran, cypermethrin and fenvalerate in Metaphire posthuma and Eisenia fetida-a possible mechanism. Ecotoxicol. Environ Saf,100, 218225.

22. Senpati, B. K \& Dash, M. C. (1984).Functional role of earthworms in the decomposer subsystem. Tropical Ecology, 25(2),54-73

23. Sharma, A., Dhayal, D., Singh, O. P., Adak, T.\& Bhatnagar, R. K. (2013). Gut microbes influence fitness and malaria transmission potential of Asian malaria vector Anopheles stephensi. Actatropica, 128(1), 41-47.

24. Singh, J. S. \& Gupta, V. K.(2018). Soil microbial biomass: A key soil driver in management of ecosystem functioning. Sci. Total. Env.,634, 497-500, https://doi.org/10.1016/ j.scitotenv.2018.03.373 (2018). 
25. Sizmur, T., B. Palumbo-Roe, M.J. Watts \& M.E. Hodson . (2011a). Impact of the earthworm Lumbricus terrestris (L.) on $\mathrm{As}, \mathrm{Cu}, \mathrm{Pb}$ and $\mathrm{Zn}$ mobility and speciation in contaminated soils. Environ. Pollut., 159, 742-748

26. Sizmur, T., Tilston, E.L., Charnock, J., Palumbo-Roe, B., Watts, M.J. \&Hodson, M.E. (2011b). Impacts of epigeic: Anecic and endogeic earthworms on metal and metalloid mobility and availability. J. Environ. Monit, 13, 266-273.

27. Staley, C., Breuillin-Sessoms, F., Wang, P., Kaiser, T., Venterea, R.T., Sadowsky, M.J. (2018) Urea Amendment Decreases Microbial Diversity and Selects for Specific Nitrifying Strains in Eight Contrasting Agricultural Soils. Frontiers in Microbiology, 9, 634.

28. Thakur, S. S. \& Yadav, S. ( 2018). Exploration of earthworms of India through Online Digital Library, Earthworms - The Ecological Engineers of Soil, Sajal Ray, IntechOpen, DOI: 10.5772/intechopen.75666. Available from: https:// www.intechopen.com/books/earthworms-the-ecological- engineers-of-soil/exploration-of-earthworms-of-india-

through-online-digital-library

29. Whalen, J. K., Parmelee, R. W. \& Edwards C. A. (1998). Population dynamics of earthworm communities in corn agroecosystems receiving organic or inorganic fertilizer amendments. Biology and Fertility of Soils, 27(4),400407.

30. Yahyaabadi, M.,Hamidian, H.A \& Ashrafi, S. (2018). Dynamics of earthworm species at different depths of orchard soil receiving organic or chemical fertilizer amendments. Eurasian J Soil Sci, 7 (4), 318 - 325.

31. Yasmin S, D'Souza D.( 2010).Effects of Pesticides on the Growth and Reproduction of Earthworm: A Review. Appl and Environ Soil Sci.1-9. 2010. Article ID 678360.

32. Zhou, S., Duan, C., Wang, X., Michelle, W.H.G., Yu, Z. \& $\mathrm{Fu}, \mathrm{H}$. (2008). Assessing cypermethrin-contaminated soil with three different earthworm test methods. J. Environ. Sci, 20(11), 1381-1385. 